\title{
Dementia associated with Parkinson's disease
}

\author{
Usefulness of the Movement Disorder \\ Society diagnostic criteria in Brazil
}

\author{
Paulo Caramelli
}

Parkinson's disease (PD) is the second most common neurodegenerative disorder, after Alzheimer's disease, with prevalence rates of $1.8 \%$ among the population aged 65 years and older in Europe and of $3.3 \%$ among individuals aged 64 years and older according to a Brazilian populationbased study ${ }^{1,2}$.

Although motor dysfunction is regarded as the main clinical feature of PD, non-motor symptoms have been increasingly recognized as important features of the disease. Among these, cognitive impairment and dementia are of special relevance, since they occur at a high rate, especially in elderly patients, and significantly contribute to disability ${ }^{3}$. In a systematic review, dementia associated with PD (PD-D) was reported in 31.3\% (95\% CI 20.1-42.1) of PD patients and was responsible for $3.6 \%$ of all dementia cases arising in the population aged 65 years and older ${ }^{4}$. However, the methods for case ascertainment varied substantially across the studies and this might be a major reason for the discrepancies on the prevalence rates found in the different surveys, which account for the wide confidence interval mentioned above.

In 2007 the Movement Disorder Society (MDS) has proposed specific diagnostic criteria for PD-D, an important initiative not only for allowing more methodologically adequate epidemiological surveys, but also for case selection in pro- spective studies, including clinical trials ${ }^{5}$. Moreover, the MDS also published recommendations for the diagnostic procedure, both a brief screening approach (Level I), which can be easily used by clinicians with no expertise in cognitive evaluation, and a comprehensive assessment (Level II), that is more suitable for dementia staging, research purposes and also for clinical trials ${ }^{6}$.

Since both these sets of recommendations have been proposed only four years ago, it is clearly necessary to conduct studies aiming at determine their sensitivity and specificity, as well as their positive and negative predictive values, in diagnosing PD-D in different countries and populations.

With this scenario as background, the study published by Baldivia and colleagues in the current issue of Arquivos de NeuroPsiquiatria represents an important contribution to the field ${ }^{7}$. The authors investigated the prevalence of PD-D according to the MDS diagnostic criteria, comparing the prevalence rates defined by the two levels of assessment. They consecutively enrolled a sample of 90 PD patients, from which 67 fulfilled their inclusion criteria and were submitted to a careful evaluation. Sixteen patients had dementia according to Level II assessment, indicating a prevalence of PD-D of $23.8 \%$ in the sample. This prevalence rate changed substantially with the adoption of the Level I assessment for the diagnosis of dementia. In
Correspondence Paulo Caramelli

Av. Prof. Alfredo Balena, 190 / Sala 246 30130-100 Belo Horizonte MG- Brasil E-mail: caramelli@ufmg.br
DEMÊNCIA ASSOCIADA À DOENÇA DE PARKINSON: UTILIDADE DOS CRITÉRIOS DIAGNÓSTICOS DA MOVEMENT DISORDER SOCIETY NO BRASIL

'Professor Adjunto, Departamento de Clínica Médica da Faculdade de Medicina da Universidade Federal de Minas Gerais, Belo Horizonte MG, Brasil. 
this case, 10 patients $(14.9 \%$, or less than $2 / 3$ of the cases identified through Level II approach) were demented, yielding low sensitivity but good specificity in detecting PD-D (31.2\% and 90.2\%, respectively).

The researchers also investigated clinical features associated with the diagnosis of dementia in their sample. In comparison with non-dementia subjects, PD-D patients were significantly older, presented an older age of onset of PD, were less educated and, as expected, were more functionally impaired. The authors also found that current age and more advanced disease (indicated by higher scores in the Hoehn and Yahr scale) were significantly associated with dementia.

In conclusion, the study by Baldivia and co-workers confirms that dementia is common in PD, independently from which MDS diagnostic approach is used. Age is a major risk factor for dementia in general and also in PD, and since these patients are leaving longer, it will become even more relevant. Hence, neurologists and clinicians who assist PD patients should incorporate cognitive testing as a routine in their work-up assessments. There are several tools that can be used by physicians for this pur- pose, although for almost all of them specific educationadjusted cut-off values must be adopted, whenever available. Finally, the study points out that the prevalence rates of PD-D may vary considerably and this feature must be taken into account by investigators in future epidemiological and clinical studies.

\section{REFERENCES}

1. de Rijk MC, Launer LJ, Berger K, et al. Prevalence of Parkinson's disease in Europe: a collaborative study of population-based cohorts. Neurology 2000;54(Suppl 5):S21-S23.

2. Barbosa MT, Caramelli P, Maia DP, et al. Parkinsonism and Parkinson's disease in the elderly: A community-based survey in Brazil (the Bambuí Study). Mov Disord 2006;21:800-808.

3. Weintraub D, Moberg PJ, Duda JE, Katz IR, Stern MB. Effect of psychiatric and other nonmotor symptoms on disability in Parkinson's disease. J Am Geriatr Soc 2004;52:784-788

4. Aarsland D, Zaccai J, Brayne C. A systematic review of prevalence studies of dementia in Parkinson's disease. Mov Disord 2005;20:1255-1263.

5. Emre M, Aarsland D, Brown R, et al. Clinical diagnostic criteria for dementia associated with Parkinson's disease. Mov Disord 2007;22:1689-1707.

6. Dubois B, Burn D, Goetz C, et al. Diagnostic procedures for Parkinson's disease dementia: Recommendations from the Movement Disorder Society Task Force. Mov Disord 2007;22:2314-2324.

7. Baldivia B, Brucki SMD, Batistela S, Esper JC, Augusto CD, Rocha MSG. Dementia in Parkinson's disease: a Brazilian sample. Arq Neuropsiquiatr 2011 69:733-738. 